\title{
A oralidade como fonte para a escrita das Histórias Indígenas
}

\author{
Orality as a source for the writing of Indigenous Histories
}

João Mitia Antunha Barbosa ${ }^{1}$

Roseline Mezacasa ${ }^{2}$

Marcelo Gonzalez Brasil Fagundes ${ }^{3}$

DOI: http://dx.doi.org/10.20435/tellus.v18i37.558

\begin{abstract}
Resumo: Considerando a forma como a historiografia tem observado a oralidade das sociedades indígenas nos estudos etno-históricos, propomos refletir sobre caminhos teóricos e metodológicos para a escrita das Histórias Indígenas, no que concerne à utilização da tradição oral como fonte de pesquisa histórica. Para tanto, contextualizaremos a emergência do protagonismo indígena na história do Brasil e os debates em torno da oralidade e historicidade desses povos. Debateremos as aproximações entre a história oral e a etnografia através da necessidade de experiências polifônicas em trabalhos acadêmicos. Conclui-se a necessidade de aproximar a história oral da etnografia no que tange aos trabalhos de campo do historiador com populações indígenas. O engendrar-se da história oral e da etnografia no saber-fazer do historiador torna-se instrumento para acessar as histórias indígenas e também possibilita escrevê-la junto dos seus protagonistas indígenas.
\end{abstract}

Palavras-chave: história indígena; história oral; etnografia.

Abstract: Considering the way in which historiography has observed the orality of indigenous societies in ethno-historical studies, we propose to reflect on theoretical and methodological paths for the writing of Indigenous Histories, regarding the use of oral tradition as a source of historical research. To do so, we will contextualize the emergence of indigenous protagonism in the history of Brazil and the debates around the oral and historicity of these peoples. We will discuss the approximations between oral history and ethnography through the need for polyphonic experiences in academic work. We conclude the need to approximate the oral history of ethnography with regard to the historian's fieldwork with indigenous populations. The engendering of oral history and

\footnotetext{
${ }^{1}$ Fundação Nacional do Índio (FUNAI), São José, Santa Catarina, Brasil.

${ }^{2}$ Universidade Federal de Rondônia, Rolim de Moura, Rondônia, Brasil.

${ }^{3}$ Universidade Federal do Tocantins, Porto Nacional, Tocantins, Brasil.
} 
ethnography in the historian's know-how becomes an instrument for accessing indigenous histories and also makes it possible to write it with its indigenous protagonists.

Keywords: indigenous history; oral history; ethnography.

\section{INTRODUÇÃO}

Então, entreguei a você minhas palavras e lhe pedi para levá-las longe, para serem conhecidas pelos brancos, que não sabem nada sobre nós. Ficamos muito tempo sentados, falando, em minha casa, apesar das mutucas e piuns. Poucos são os brancos que escutaram nossa fala desse modo. [...] Mais tarde, eu disse a você: "Se quiser pegar minhas palavras, não as destrua. São as palavras de Omama e dos xapiri. Desenhe-as primeiro em peles de imagens, depois olhe para elas. Você vai pensar: "Haixopë! É essa mesmo a história dos espíritos!". E, mais tarde, dirá a seus filhos: "Estas palavras escritas são as de um Yanomami, que há muito tempo me contou como ele virou espírito e de que modo aprendeu a falar para defender a sua floresta". Depois, quando essas fitas em que a sombra das minhas palavras está presa ficarem imprestáveis, não as jogue fora. Você só vai poder queimá-las quando ficarem muito velhas e minhas falas tiverem já há muito tempo sido tornadas desenhos que os brancos podem olhar. Inaha tha? Está bem? (KOPENAWA; ALBERT, 2015, p. 63-4)

As palavras de Kopenawa nos levam a refletir sobre o processo de apreensão da oralidade pelo pesquisador. As sombras das "palavras dadas" são aprisionadas pelo entrevistador, que as coloca em peles de imagens e assim podem ser observadas pelos outros. Nos tempos recentes, registrar e desenhar essas palavras dadas também é um método utilizado pelos pesquisadores indígenas, e não somente direcionado ao mundo dos "brancos" - como veremos adiante.

Esse processo de uso da fonte oral para pesquisas que envolvam populações indígenas contemporâneas engendra o saber-fazer capaz de articular arcabouços teóricos interdisciplinares. No entanto o debate teórico-metodológico em torno do uso da oralidade nos estudos com populações indígenas pela historiografia ainda é pouco explorado.

A história indígena tem apresentado importante desenvolvimento no curso das últimas décadas, mas são poucos estudos historiográficos em que os povos indígenas são protagonistas na construção de um ponto de vista sobre o 
passado. A tradição oral desses povos apresenta-se como aspecto inerente à problematização metodológica pensada a partir das pesquisas que tenham esse viés. O fortalecimento desse campo historiográfico, no entanto ainda descortina caminhos profícuos no que diz respeito a metodologias de pesquisa. A história oral apresentou-se como metodologia por excelência das temáticas do tempo presente e dos estudos dos grupos subalternos ou populares, contudo, em alguns trabalhos historiográficos, a etnografia também tem sido utilizada como ferramenta de pesquisa.

No presente artigo, procuramos observar possibilidades teóricas e metodológicas para as pesquisas historiográficas embasadas na tradição oral dos povos indígenas. Para tanto, contextualizaremos o desenvolvimento da história indígena no Brasil e o uso da oralidade como fonte historiográfica de construção de histórias indígenas. Destacaremos os debates em torno da história oral e suas aproximações com a pesquisa etnográfica. A transposição do oral para o escrito através da transcrição e transcriação é debatida a partir de uma pesquisadora indígena. Dessa forma, destaca-se ao longo do texto que a aproximação entre história oral e etnografia engendra ao saber-fazer do historiador importantes instrumentos metodológicos para a escrita das histórias indígenas.

\section{ORALIDADE E HISTÓRIA INDÍGENA}

Os povos indígenas, por muito tempo, foram taxados pelo conhecimento científico enquanto a-históricos, sobrando a estes apenas a etnografia, em alusão ao presente etnográfico (Cf. CUNHA, 1992; MONTEIRO, 1995). O conhecimento historiográfico se constituiu por sujeitos que, imbuídos dos temas e pensamentos do seu tempo, pensaram o passado a partir de inúmeras construções sociais, inclusive construções que impunham uma normatização do conceito de história e consequentemente de quais grupos humanos a possuíam ou não. Nesse debate, não podemos deixar de citar Francisco Adolfo Varnhagen, que, na sua célebre expressão da segunda metade do século XIX a respeito dos índios e da história, deixou marcas que percorreram o século XX. Segundo o autor, para os indígenas "não há história, há apenas etnografia" (VARNHAGEN apud MONTEIRO, 1995, p. 221). Nesse contexto, repensar a história conceitual do que foi considerado história ou não remete ao pensar sobre a essência de nossa disciplina e, consequentemente, 
às violências epistêmicas que foram impostas aos povos indígenas considerados a-históricos.

A construção da narrativa historiográfica dos "povos sem história" - para usar a expressão de Eric Wolf - operou através de um processo de silenciamento que acabou por impor uma concepção hegemônica de historicidade. No que tange à história dos grupos indígenas, o silenciamento se deu através da construção de uma lógica em que estes se encontravam na estaca zero da evolução e, portanto, como sociedades "primitivas" que haviam parado no tempo (CUNHA, 1992). Tanto o historicismo, como o evolucionismo, que tiveram seu destaque no século XIX, utilizaram de analogias temporais para diferenciar as sociedades humanas, posicionando-as em uma escala temporal determinada pela "evolução" (tecnológica) de dada "civilização". A antropologia, na primeira metade do século XX, advogava a necessidade do distanciamento da história para compor as etnografias. Segundo Thiago Cavalcante, a antropologia "[...] se dedicava ao estudo das culturas nativas não ocidentais consideradas inferiores e estáticas, culturas a-históricas, portanto. Já a história devia se preocupar com as culturas de origem europeia, ávidas pela mudança e especialmente letradas, o que permitia produzir e deixar muitos documentos escritos sobre o próprio passado" (CAVALCANTE, 2011, p. 354).

Nesse cenário, os índios tiveram pouca expressão na composição da História do Brasil. Retomamos a frase de Manuela Carneiro da Cunha, ao escrever a introdução do clássico História dos índios no Brasil, quando afirmou que "[...] também a História do Brasil, a canônica, começa invariavelmente pelo 'descobrimento'. São os 'descobridores' que a inauguram e conferem aos gentios uma entrada- de serviço- no grande curso da História” (CUNHA, 1992, p. 9). Cunha, ávida crítica do silenciamento dado pela historiografia à presença indígena na História do Brasil, é enfática ao estabelecer a crítica à história tradicional.

Entretanto essa conjuntura alterou-se sobretudo a partir da década de 1980. O fenômeno histórico do surgimento dos movimentos indígenas e a luta pelo reconhecimento dos direitos originários desses povos no âmbito da elaboração da Constituição de 1988 levaram a um redimensionamento do papel dos indígenas na história do Brasil. A partir desse processo, colocou-se em xeque a tese de desaparecimento dos povos indígenas, e estes passaram a emergir como protagonistas de sua própria história. Segundo Monteiro (1995): 
A principal voz discordante, em enfática negação da tese do desaparecimento, pertence aos próprios índios que, através de novas formas de expressão política - tais como as organizações indígenas -, reivindicam e reconquistam direitos históricos. O novo indigenismo, por seu turno, encontrou, desde a primeira hora, fortes aliados no meio antropológico, que passaram a pautar suas pesquisas não apenas a partir de interesses acadêmicos mas também pela necessidade de fornecer subsídios para as lutas e reivindicações dos índios. Assim, surge uma nova bibliografia que tem contribuído não apenas para ampliar a visibilidade de povos indígenas numa história que sempre os omitiu, como também revela as perspectivas destes mesmos povos sobre seu próprio passado, incluindo visões alternativas do contato e da conquista. (MONTEIRO, 1995, p. 223).

A emergência do protagonismo dos povos na luta por direitos políticos, além dos estudos voltados para o reconhecimento dos direitos territoriais desses povos, impôs aos historiadores o desafio de considerar a tradição oral dessas populações. A emergência do reconhecimento, até então negado, dos indígenas como sujeitos históricos reforçou a necessidade de uma maior preocupação teórica e metodológica do olhar historiográfico sobre essas populações.

Para o pesquisador Jorge Eremites de Oliveira, como também para outros estudiosos, a historiografia que se produziu foi eurocêntrica e evolucionista:

[...] historiografia que tem, pois, na trajetória dos povos europeus o seu epicentro espaço-temporal, quer dizer, o eixo pelo qual se percebe, especialmente por meio da cientificidade construída no Ocidente a partir do Iluminismo, toda a história da humanidade. Seria como se a Europa fosse o sol, o astro-rei, e os demais continentes os planetas que giram ao seu redor. (OLIVEIRA, 2012, p. 187).

Dessa forma, após a década de 1980, os historiadores começam a preocupar-se com a "entrada de serviço" conferida aos índios na história do Brasil, como também com a história eurocêntrica e evolucionista, e, então, em uma construção teórica e metodológica, passam a reconhecer as historicidades indígenas anteriores ao contato com os europeus, além de procurar compreender os processos históricos complexos pelos quais passaram os indígenas no pós-contato. As perguntas historiográficas dessa proposta de História Indígena, que se consolidou na década de 1990, principalmente após o lançamento em 1992 do livro História dos índios no Brasil (OLIVEIRA, 2012), citado anteriormente, perpassam a perspectiva de compreender tais sujeitos enquanto protagonistas, 
evidenciando as multiplicidades de relações, possibilidades, agências em que se engendram as historicidades indígenas ${ }^{4}$.

Antonio Jacó Brand, em 1997, defendeu sua tese de doutoramento em História, intitulada O impacto da perda da terra sobre a tradição Kaiowá/Guarani: os dificeis caminhos da palavra. Sua tese foi precursora para os trabalhos historiográficos que tinham na oralidade um caminho teórico e metodológico significativo para o que hoje chamamos de História Indígena, a partir do tempo presente. 0 historiador tratou em seu trabalho dos impactos sofridos pelos Kaiowá/Guarani no processo de perda dos seus territórios tradicionais, fruto das dispersões impostas pelas violentas territorializações empenhadas pelos sujeitos do Estado brasileiro, como também, por fazendeiros na região do Cone-Sul de Mato Grosso do Sul. As lacunas documentais eram evidentes, o que tornava a oralidade importante para acessar os universos indígenas Kaiowá/Guarani. Dessa forma, no primeiro capítulo de sua tese já destacava "[...] ante as limitações já apontadas na documentação existente, impõem-se não só a produção de uma nova documentação, mas a busca de novos enfoques, ou de novas leituras históricas [...] esta nova leitura emerge exatamente da transformação do objeto de pesquisa em sujeito com o qual o pesquisador dialoga" (BRAND, 1997, p. 26). E nessa perspectiva, o autor construiu sua pesquisa, pautando-se na "[...] escuta da fala indígena [...]" (BRAND, 1997, p. 272), o que descortinou "uma visão ampla e articulada das diversas facetas inerentes aos Kaiowá/Guarani" (BRAND, 1997, p. 272).

Em 2004, o historiador Edinaldo Bezerra de Freitas publicou o artigo intitulado "Fala de índio, História do Brasil: o desafio da Etno-História indígena", onde afirma que a história oral insere-se "na busca do diálogo com o outro, implicando aí um diálogo entre o passado e o presente, [...] com o diferente, com o esqueci-

\footnotetext{
${ }^{4}$ É importante distinguir algumas acepções para a noção de historicidade. É preponderante na historiografia o entendimento de historicidade como condição inerente das ideias, dos objetos e das pessoas que estão inscritas em sua condição histórica. Muitas dessas pesquisas se propõem a "historicizar" os objetos, os conceitos e os indivíduos, reconhecendo uma "historicidade" inerente às coisas. Para Hartog (2014), historicidade "expressa a forma da condição histórica, a maneira como um indivíduo ou uma coletividade se instaura e se desenvolve no tempo" (p. 12). Para Fausto e Heckenberger (2007), historicidade é entendida como as distintas formas em que as coletividades humanas entendem o tempo, e como se relacionam com o passado e com o futuro. As distintas acepções do conceito, bem como a confusão metodológica gerada pela complexificação do debate, são desafios a serem mais bem desenvolvidos na tentativa de incorporar historicidades distintas no âmbito da historiografia.
} 
do [...] construção de um saber, comprometido com a experiência de vida desse outro" (FREITAS, 2004, p. 185). Freitas (2004) ainda apontou que poucos estudos de história oral se dedicavam aos povos indígenas brasileiros. Entre os trabalhos citados, o autor destacou a publicação de Bom Meihy, Canto de morte kaiowá ${ }^{5}$ (1991), sobre as narrativas de índios Guarani Kaiowá transcritas na íntegra. O livro de Meihy não apresenta contextos e interpretações, demonstrando a filiação do autor a uma tradição de história oral que se prende ao ato de transcrição e transcriação dos textos orais. A proposta de Meihy, embora também seja história oral, é diferente do trabalho de Antonio Brand, acima citado, tendo em vista que o último dialoga com a oralidade indígena enquanto fonte para a escrita historiográfica, para então compreender os processos pelos quais os Kaiowá-Guarani passaram na perda de seus territórios tradicionais, incluindo na construção historiográfica um conjunto de entrevistas, além da análise documental.

A construção da história a partir da história oral ainda possibilita, segundo Freitas, "[...] dialogar com 'o outro', e dessa forma, fazer história oral indígena, então, é realizar essa tarefa de maneira mais profunda possível, pois se trata de contatar 'o outro' no sentido pleno da conceituação cultural” (FREITAS, 2004. p. 187).

Em 2010, o historiador Giovani José da Silva e a antropóloga Joana Aparecida Fernandes Silva publicaram artigo intitulado "História indígena, antropologia e fontes orais: questões teóricas e metodológicas no diálogo com o tempo presente", em que analisaram a utilização das fontes orais nos estudos de história indígena e as especificidades do trabalho de campo etnográfico. Mesmo tendo se passado seis anos da publicação do artigo de Freitas (2004), em que este sinaliza sobre a baixa produção em história oral que envolva os povos indígenas, em 2010, Silva e Silva também expressam a mesma constatação sobre a pouca produção no Brasil que utiliza história oral para construir as histórias indígenas e, consequentemente, poucas reflexões teórico-metodológicas sobre o assunto.

Silva e Silva (2010) são enfáticos na valorização das fontes orais indígenas para a escrita historiográfica,

[...] a experiência de se deslocar do etnocentrismo e de apreender que há muitas outras soluções possíveis para o viver e outras saídas para a escrita da história vivida. Escrever história, a partir do ponto de vista dos grupos

${ }^{5}$ MEIHY, J. C. S. B. Canto de Morte Kaiowá. São Paulo: Edições Loyola, 1991. 
indígenas, enfatiza-se, é também um dever dos historiadores. As vozes indígenas têm sido condenadas ao silêncio, por meio do genocídio sofrido pelos índios, da invisibilização ou de um sistemático processo de se ignorar sua presença pretérita e presente. (SILVA; SILVA, 2010, p. 47).

Eles apontam ainda que as pesquisas que envolvem as tradições orais indígenas são mais abundantes no contexto latino e norte-americano ${ }^{6}$.

\footnotetext{
${ }^{6}$ Observando os distintos contextos globais em que se desenvolvem pesquisas que envolvam a tradição oral de povos indígenas - onde há espaço reflexivo para as inquietações dos pesquisadores nesse campo -, podemos evidenciar alguns caminhos teóricos e metodológicos incorporados às pesquisas. O historiador Jan Vansina (1985) representa uma das pioneiras tentativas de sistematizar a tradição oral em contextos indígenas. Em 1985, publicou Oral Tradition as History, onde procurou apontar características gerais da tradição oral enquanto evidência histórica, baseada na experiência de pesquisa na África central. A tradição oral, vista como processo, é resultado de mensagens orais constituídas a partir do presente do informante. Vansina diferencia dessa forma a história oral, contemporânea, do que vai se tornar mais tarde tradição oral. Apesar de apresentar certa rigidez própria de um roteiro metodológico voltado para os historiadores orais na análise das mensagens orais -, a obra de Vansina possui papel importante para problematizar a oralidade de sociedades indígenas. Em 1994, a antropóloga norte-americana Julie Cruikshank já considerava as tradições orais indígenas enquanto abordagem historiográfica válida e alertava que no contexto canadense os povos indígenas exigiam que suas tradições orais fossem levadas a sério como visões legítimas da história (CRUIKSHANK, 2006, p. 151). A tradição oral, nesta perspectiva, é vista como um sistema coerente e aberto para construir e transmitir conhecimentos. Os relatos orais, produzidos em contextos culturais distintos, caracterizados pela subjetividade inerente, devem ser ouvidos no contexto específico em que são produzidos. Os acontecimentos inter-relacionam a territorialidade, a espacialidade e a temporalidade dos grupos humanos e, dessa forma, "as tradições indígenas tornam o lugar fundamental para a compreensão do passado, e mapeiam os eventos ao longo de montanhas, trilhas e rios que ligam territórios" (CRUIKSHANK, 2006, p. 162). No livro Long History, Deep Time: Deepening Histories of Place, publicado em 2015 na Austrália, a convergência de pesquisadores de várias áreas tem pensado as histórias indígenas a partir de diferentes métodos de pesquisa, mas que tenham enquanto fio condutor a historicidade dos povos tidos por muito tempo como sendo "sem história". Ann McGrath, organizadora do livro, sobre o desafio de escrever uma "história profunda indígena", é enfática ao problematizar o tempo historicizado na história ocidental. Para a autora, quando se trata de povos indígenas tal perspectiva deve ser ampliada e complexificada, pois inúmeras variáveis, entre elas as experiências dos grupos em diferentes territórios, cosmologias, saber-fazer, compõem as historicidades indígenas. Entretanto, se a análise historiográfica não se apropriar desses dinamismos da existência indígena, tampouco conseguirá escrever histórias indígenas, e apenas vai continuar a reproduzir referências ao índio a-histórico, estático no tempo, limitando a complexidade da existência indígena (MCGRATH, 2015, p. 6). Outra experiência frutífera tem sido realizada nos Estados Unidos, onde foi publicado em 2008 o livro The American Indian Oral History Manual: Making Many Voices Heard). Nessa publicação, escrita por Charles Trimble, membro da etnia Oglala Sioux, com coautoria de Barbara Sommers e Mary Kay Quinlan, a proposta é auxiliar metodologicamente a construção de trabalhos de história oral feitos por pesquisadores indígenas (TRIMBLE; SOMMERS; QUINLAN, 2008, p. 9). O livro ressalta os códigos legais e étnicos que envolvem a oralidade entre os grupos indígenas, destacando que por muito tempo os pesquisadores "estrangeiros" não levaram em consideração as dinâmicas da oralidade indígena.
} 
Ao analisarmos as comunicações orais dedicadas à história indígena nos Simpósios Nacionais de História, entre os anos de 2013 e 2017, percebemos um aumento das pesquisas sobre a temática. No entanto apenas uma parcela reduzida utiliza-se da oralidade como fonte de pesquisa. No último simpósio nacional, realizado na cidade de Brasília, DF, em julho de 2017, das comunicações com artigo completo em anais, destacamos as pesquisas de Machado (2017) e Teao (2017). A pesquisa de Machado (2015; 2017) propõe pensar as políticas de uso da língua Wapichana e aponta para o uso da história oral, mas com o suporte transdisciplinar da etno-história. Já Teao (2015; 2017), que estuda a identidade Guarani Mbya no Espírito Santo, destaca o uso de fontes orais em suas pesquisas e a etno-história como ferramenta de leitura dessas fontes.

Os Programas de Pós-Graduação em História também têm ampliado as pesquisas voltadas à história indígena, mas novamente são poucas as pesquisas voltadas às comunidades indígenas contemporâneas que problematizam o uso de fontes orais. ${ }^{7}$ Entre as teses defendidas recentemente nesses Programas, destacamos as teses de Mauro (2016), da Universidade Federal da Grande Dourados (UFGD), que se ancora nos preceitos da etnografia, e de Crespe (2015), também da UFGD e de Almeida (2015), da Universidade Federal de Santa Catarina (UFSC), que dialogam com da história oral. Obviamente existem outras teses historiográficas de história indígena com uso de fontes orais, no entanto não aprofundam questões metodológicas em torno dessas fontes.

Nesse contexto, não há dúvida de que a história oral é metodologicamente uma ferramenta importante para acessar as experiências indígenas e, assim,

\footnotetext{
${ }^{7}$ Realizamos uma pesquisa junto aos Programas de Pós-Graduação em História de diversas universidades em diferentes regiões do país (Universidade Federal do Pará - UFPA; Universidade Federal do Amazonas - UFAM; Universidade Federal da Grande Dourados - UFGD; Universidade Estadual de Campinas - UNICAMP; Universidade de São Paulo - USP; Universidade Federal Fluminense - UFF; Universidade Federal do Rio de Janeiro - UFRJ; Universidade Federal do Paraná - UFPR; Universidade Federal de Santa Catarina - UFSC. Universidade Federal do Rio Grande do Sul UFRGS; Universidade do Vale do Rio dos Sinos - UNISINOS e Pontifícia Universidade Católica do Rio Grande do Sul-PUCRS). A análise se baseou em teses de doutoramento defendidas recentemente, inseridos no campo da história indígena e que, de alguma forma, trabalham com a oralidade das sociedades indígenas. O recorte temporal dessa análise variou de programa para programa em virtude da disponibilidade de teses digitais. Portanto, a investigação feita certamente não atingiu a completude das pesquisas realizadas. No entanto, a partir desse amplo levantamento foi possível vislumbrar, de maneira geral, as opções metodológicas adotadas pela historiografia no trato das fontes orais oriundas de comunidades indígenas contemporâneas.
} 
evidenciar as historicidades desses sujeitos. Com as oralidades, o historiador encontra os elementos que compõem e compuseram a "arena social" desses sujeitos na constituição de suas historicidades. Entretanto podemos constatar a ausência de debates aprofundados sobre teoria e método do uso de fontes orais nesse contexto.

\section{APROXIMAÇÕES ENTRE HISTÓRIA ORAL E ETNOGRAFIA}

A história oral torna-se uma ferramenta ao ofício da História na década de 1970 em países como França, Itália, Estados Unidos, entre outros. A utilização de novas metodologias de pesquisa vem abalar os pilares rigidamente assentados, e auxilia a repensar a posição em que "[...] a história se constituiu cientificamente, desde o século XVII, a partir da crítica da tradição oral e, mais genericamente, do testemunho" (JOUTARD, 2006 , p. 43), pautando-se na documentação escrita enquanto fonte fidedigna para a escrita historiográfica. Como bem exemplificou Burguière, a "história ficou presa ao status do público, do político, do fato histórico 'que irrompe na esfera pública'” (BURGUIÈRE, 2011, p. 301).

Os grandes eventos da história, tais como a Segunda Guerra Mundial, propiciaram e fortaleceram o crescimento de uma "história alternativa, não apenas em relação à história acadêmica, mas também em relação a todas as construções historiográficas baseadas no escrito" (JOUTARD, 2006, p. 46). As demandas em acessar novos temas de pesquisas que descortinavam nas conjunturas mundiais e que seriam impossíveis, se pensada uma história somente a partir da análise da documentação escrita, somaram para o amadurecimento da utilização de fontes orais nos trabalhos de história. Assim, a história oral está preocupada com os “'nuevos sujetos sociales', con el propósito de abordarlos en 'escalas y niveles locales y regionales', para buscar y comprender fenómenos sociohistóricos particulares, mediante la producción de 'nuevas fuentes' de información y evidencia histórica" (ACEVES, 1996, p. 10).

Entende-se aqui história oral a partir de Verena Alberti, enquanto "[...] um método de pesquisa [...] que privilegia a realização de entrevistas com pessoas que participaram de, ou testemunharam, acontecimentos, conjunturas, visões de mundo, como forma de se aproximar do objeto de estudo" (ALBERTI, 2005, p. 18). Dessa forma, a história oral congrega-se enquanto método de acesso a 
narrativas orais, que parte de um conjunto metodológico, tais como a entrevista e a transcrição, para sua utilização no trabalho historiográfico.

Metodologicamente, o saber-fazer que envolve a prática da história oral, como se convencionou, detém-se em entrevistas estruturadas ou semiestruturadas, agendadas com os sujeitos da entrevista e, em alguns casos, a utilização de caderno de campo. Após a entrevista, encaminha-se para a etapa da transcrição da entrevista. Ainda, posteriormente, alguns pesquisadores antes de utilizar a narrativa, visitam novamente o entrevistado para, a partir do escrito, ter a autorização para a utilização. Após essa fase, o historiador tem então a sua fonte produzida, pronta ao crivo de sua análise historiográfica. Tal metodologia já é passiva de dar ao pesquisador dados necessários para a sua pesquisa. Entretanto, neste artigo, queremos advogar pelo cruzamento entre história oral e etnografia nas pesquisas de historiadores com populações indígenas no tempo presente, na perspectiva do cruzamento propiciar melhores situações de campo, que vão fornecer melhores compreensões da complexa dinâmica sociais dos povos indígenas.

A aproximação entre a história oral e a antropologia tem um ponto de inflexão em 1976, quando acontece, em Bolonha, o primeiro colóquio internacional de história oral, intitulado: Antropologia e História: fontes orais (JOUTARD, 2006, p. 46). Dessa forma, o trabalho no campo da história que utiliza oralidades, sem dúvida, deve pensar o diálogo interdisciplinar com a antropologia, pois, em muito elas se aproximam; Freitas, em 2004, ressaltava que "uma história oral indígena exige um certo grau de ofício etnográfico e etnológico” (FREITAS, 2004, p. 187).

Ainda na década de 1970, grandes projetos que se utilizavam da metodologia da história oral envolviam não apenas historiadores, mas também linguistas e antropólogos (JOUTARD, 2006, p. 47). Joutard chamou de uma história oral antropológica o que se descortinou na década de 1970. Na sua essência, segundo o autor, ela se preocupava com "temas que se acham presentes nas diversas experiências nacionais" (JOUTARD, 2006, p. 51). Essa história oral antropológica, "[...] que dá voz aos excluídos e trata de temas da vida cotidiana, não surpreende a história acadêmica somente por sua fonte, mas também por seu objeto e suas problemáticas" (JOUTARD, 2006, p. 52). A história oral emerge de uma crítica aos modelos historiográficos da época, propondo novos objetos e problemáticas, hoje consagrados enquanto produção historiográfica, entretanto, não sem antes travar uma "batalha" contra os adeptos da história tradicional. 
Na primeira metade do século XX, o trabalho de campo intensivo "realizado por especialistas treinados na universidade, emergiu como uma fonte privilegiada e legitimada de dados sobre povos exóticos" (CLIFFORD, 2008, p. 20). A esse saber-fazer nomeou-se de observação participante. Embora o método etnográfico também esteja passando por críticas, ele é o instrumento chave para a construção de trabalhos na área de antropologia. O antropólogo envolve-se com o grupo/comunidade construindo uma etnografia, pautada na observação participante. Expoentes desse método, ainda na primeira metade do século XX, foram os trabalhos de Franz Boas, Bronislaw Malinowski e Margaret Mead. Esse método inaugurou uma nova fase para antropologia, que anteriormente era feita sobretudo por antropólogos que permaneciam em seus gabinetes, escrevendo a partir dos relatos de missionários, viajantes.

Roberto Cardoso de Oliveira, no livro O trabalho do antropólogo, destaca que a etnografia funda-se nas etapas do olhar, ouvir e escrever (OLIVEIRA, 2000) para construir um dado saber/conhecimento sobre determinada situação social/ cultural, a partir de um conjunto de pressupostos teóricos que constituem o "olhar etnográfico".

Encontramos muitas afinidades no saber-fazer do historiador e do antropólogo; dessa forma, os diálogos são caminhos frutíferos para os historiadores em territórios indígenas. Inúmeras questões perpassam esse saber-fazer. Entre eles, vale destacar o ouvir e o olhar (OLIVEIRA, 2000). Sobre o ouvir, o historiadores já estão familiarizados, a história oral propiciou amadurecimentos nesse campo. Entretanto a necessidade do olhar em múltiplos ambientes, em outras interações, em outros contextos faz a etnografia ser uma companheira necessária.

Quando ampliamos nossa noção de fontes, podemos ter a etnografia8 enquanto método para acessar as historicidades que compõem os cotidianos indígenas, que, muitas vezes, não são revelados através de entrevistas formais. Essas historicidades indígenas podem estar nas expressões da pintura corporal,

\footnotetext{
${ }^{8}$ Conforme Oliveira (2012), os estudos arqueológicos, geográficos, linguísticos [...] são fundamentais para compor a interdisciplinaridade necessária para a escrita das histórias indígenas, e então, compreender a dinamicidade dos povos indígenas. "[...] a história indígena aqui defendida possui um caráter marcadamente interdisciplinar, isto é, para além das fronteiras disciplinares, e se opõe a todo tipo de areacentrismo ou fobia em relação a outros campos do saber" (OLIVEIRA, 2012, p. 198).
} 
nos modos de fazer, modos de colher, nas relações entre humanos e não humanos, nos corpos que enfeitam-se, entre outros. Assim, a partir do olhar, outros elementos de pesquisa de campo descortinam-se ao historiador pesquisador junto aos povos indígenas (FAUSTO; HECKENBERGER, 2007). Jorge Eremites de Oliveira também coaduna com a necessária aproximação entre história e antropologia para a composição de trabalhos na área da História Indígena. Citando Maria Celestina, escreve "[...] com isso, urge a necessidade de conjugar técnicas, métodos e teorias da história e da antropologia, os quais 'vão aos poucos desconstruindo compreensões simplistas e interpretações equivocadas sobre os índios e suas relações'" (CELESTINO DE ALMEIDA, 2010, p. 10-11 apud OLIVEIRA, 2012, p. 204).

O antropólogo canadense Bruce Granville Miller, em texto que discute a utilização das narrativas orais indígenas em tribunais, também nos auxilia na importância da etnografia para os historiadores que trabalham com populações indígenas. Segundo ele, o trabalho de campo "[...] is essential to understanding the context and meaning of oral narratives. The oral narratives are always more complex than what is written about them, shorn of the context of delivery, and what is written is inevitably a truncated version of a much longer piece" (MILLER, 2011, p. 25) $)^{9}$. Assim, o olhar, o envolver-se para além de entrevistas "formais", é a possibilidade de encontrar contextos mais amplos das oralidades indígenas, que, muitas vezes, não são possíveis de serem decodificados apenas com entrevistas, em ambientes articulados a partir da presença de um gravador.

Traçados esses breves lugares da história oral e da etnografia, segue-se para uma discussão sobre o processo de tornar o oral em escrito, e talvez para o terceiro ponto do fazer etnográfico, segundo Oliveira (2000), o escrever, que também é questão para o historiador. Essa etapa do saber-fazer que transforma o oral em escrito é tema de reflexão tanto para historiadores, quanto para antropólogos. A antropologia mais contemporânea preocupa-se com o sujeito que enuncia, superando assim o discurso homogeneizante das etnografias do passado, em que grupos étnicos eram interpretados e descritos, em muito a partir da autoridade etnográfica do pesquisador, "na experiência do scholar que observava/participava (CLIFFORD, 2008, p. 33).

\footnotetext{
9 "[...] é essencial para entender o contexto e o significado das narrativas orais. As narrativas orais são sempre mais complexas do que o que está escrito sobre elas, desprovido do contexto de entrega, e o que está escrito é, inevitavelmente, uma versão truncada de uma peça muito mais longa."
} 
Na história oral comumente se utiliza a transcrição ou a transcriação da entrevista, onde o sujeito da oralidade é nomeado. Quando isso não acontece, utiliza-se outro nome, entretanto sempre se utiliza a marcação do sujeito que fala em determinado contexto, participante de determinado grupo. Assim, o sujeito da fala sempre é elemento importantíssimo e fundante da história oral, estando muito bem marcado no corpo do texto.

No livro Recording Oral History: A Guide for the Humanities and Social Sciences, a historiadora norte-americana Valerie Raleigh Yow faz um debate sobre as possibilidades para a escrita da história oral. Para ela, na transcrição, "the goal is to reproduce as closely as possible the speech of the narrator" (YOW, 2005, p. $317)^{10}$. Susan Allen, citada por Yow, é enfática na defesa da transcrição absoluta. Segundo sua proposta:

Oral history is what comes out of people's mouths, and it has to be captured accurately on paper; or else you violate the integrity of the interviewee, who has been kind enough to give you his or her time, and you violate the integrity of the medium. What is on the tape is what happened in the interview. What is on tape is what was actually said. (ALLEN apud YOW, 2005, p. 317). ${ }^{11}$

No processo de transcrição absoluta, o pesquisador transcreve seguindo as maneiras da oralidade, com os "vícios" de linguagem, seguindo a sociolinguística da oralidade. ${ }^{12}$ Outros pesquisadores vão advogar pela transcriação. Nesse processo, primeiro é feita a transcrição absoluta. Depois, para a versão final, que será utilizada na pesquisa e/ou disponibilizado em arquivos, o texto é recriado/ arrumado, no sentido de retirar vícios de linguagem, inserir pontuação etc., tendo ao final, uma nova criação.

José Carlos Sebe Bom Meihy, no livro Manual de História Oral, escreve que o processo de transcriação insere-se a partir de três etapas: transcrição ab-

10 "O objetivo é reproduzir o mais próximo possível do discurso do narrador."

11 "A história oral é o que sai da boca das pessoas, e tem que ser capturada com precisão no papel; ou então você viola a integridade do entrevistado, que tem sido gentil o suficiente para Ihe dar o tempo dele ou dela, e você viola a integridade do meio. O que está na fita é o que aconteceu na entrevista. O que está na fita é o que realmente foi dito."

${ }^{12}$ Para informações sobre tecnologias possíveis para o trabalho de transcrições, tais como software, a historiadora Yow sugere o Oral History List Service, segundo ela, "an online service of the Oral History Association at h-oralhist@h-net.msu.edu; it’s free" (YOW, 2005, p. 316). 
soluta, textualização e transcriação. Para o historiador, na fase de textualização, que segue após a transcrição absoluta, são "eliminadas as perguntas, tirados os erros gramaticais e reparadas as palavras sem peso semântico. Os sons e ruídos também foram eliminados em favor de um texto mais claro e liso" (MEIHY, 2004, p. 238). Ao final, chega-se à transcriação. Meihy, cita Daphne Patai, para quem o "importante de uma entrevista não são as palavras como elas foram ditas ou pronunciadas, e sim o seu significado no conjunto das mensagens" (MEIHY, 2004, p. 232). Sobre transcriação, o historiador italiano Portelli escreveu: "[...] minha tendência é evitar esse procedimento, porque gosto do modo de falar das pessoas" (PORTELLI, 1997, p. 40).

Silva e Silva (2010) destacaram o "aprisionamento" do oral no escrito. As experiências do ato de enunciar, sendo eles "[...] gestos, silêncios, cheiros, cores e sentimentos sutis são praticamente eliminados" (SILVA; SILVA, 2010, p. 41) no transpor para o papel as narrativas indígenas. O debate que gira em volta do tornar escrito o falado é longo e produtivo. Alguns se prendem na fidedignidade do ato, outros se preocupam com o tornar a escrita envolvente, emocionante, tanto quanto a oralidade. Diante dessas inquietações, a pesquisadora indígena Lorina Barker traz, em grande medida, elementos interessantes para auxiliar o nosso fazer na escrita das histórias indígenas, construída a partir das oralidades.

No artigo "Using Poetry to Capture the Aboriginal Voice in Oral History Transcripts", Barker (2010) aponta a importância da história oral para a história indígena:

My reason for conducting oral histories is that I believe Aboriginal histories and oral histories are intrinsically linked and for the most part have been largely ignored, misinterpreted or deemed as 'mythical' unreliable sources of knowledge by more traditionally text-based historians. In using oral histories, I am tapping into the millennia long tradition of oral storytelling as the way that Aboriginal people's history and cultural knowledge has and continues to be conveyed. (BARKER, 2010, p. 185). ${ }^{13}$

\footnotetext{
13 "O meu motivo para a realização de histórias orais é que acredito que histórias aborígenes e histórias orais estão intrinsecamente ligadas e, em sua maior parte, foram amplamente ignoradas, mal interpretadas ou consideradas como fontes de conhecimento "mítico" não confiáveis por historiadores tradicionalmente baseados em texto. Ao usar histórias orais, estou tocando na longa tradição de narrativa oral e, como a história e conhecimento cultural dos povos aborígines existem e continuam a ser transmitidas."
} 
A crítica aqui recai sobre o silenciamento do reconhecimento de suas histórias, que surgem na oralidade, nas narrativas contadas, além de chamar atenção para o necessário debate sobre a composição da história indígena a partir das oralidades - em resposta aos historiadores que desprezam essas historicidades por estarem vinculadas a outros campos do conhecimento - e não ao do escrito. Lorina Barker parte suas indagações, justamente, da insatisfação gerada ao perceber os limites ao transpor para a escrita as vozes indígenas do seu povo. Barker, enquanto sujeita de várias pesquisas, inquietava-se ao ler e não reconhecer suas narrativas transcritas por pesquisadores, sobre isso assinalou: "[...] in retrospect, I had read through the transcript trying to feel the words, to hear the conversation, but what I received in return was merely black ink on white paper, words devoid of emotion and foreign to the eye. These were not my stories and my memories" (BARKER, 2010, p. 188) ${ }^{14}$.

Esse contexto de sujeita pesquisada, mas também protagonista do fazer pesquisa, fez Lorina repensar e procurar possibilidades em outras áreas. Para ela, existia "[...] the challenges involved in converting the layered richness, sounds, silences and interactions of the memories recorded through an oral history interview into text" (BARKER, 2010, p. 186) ${ }^{15}$. Lorina encontrou nas discussões sobre a poesia de verso livre um arcabouço teórico-metodológico que a auxiliou a superar tais desafios em suas pesquisas com história oral. Dessa forma, Lorina Barker não segue a perspectiva da transcrição, como tem sido feita pela maioria dos pesquisadores, tampouco da transcriação.

Conforme Lorina, estruturalmente o verso livre possibilita uma "[...] breaks with grammar and it does not force oral speech patterns into written prose. More importantly, it does not make the research participants' words look 'inferior', ungrammatical and unpunctuated" (BARKER, 2010, p. 192) ${ }^{16}$. Para conseguir tal propósito, a partir de uma revisão bibliográfica sobre o assunto em que dialogou

14 "Em retrospecto, eu tinha lido a transcrição tentando sentir as palavras, ouvir a conversa, mas o que recebi em troca foi apenas tinta preta em papel branco, palavras desprovidas de emoção e estranhas aos olhos. Estas não eram minhas histórias e minhas lembranças."

15 "os desafios envolvidos na conversão da riqueza em camadas, sons, silêncios e interações das memórias gravadas através de uma entrevista de história oral em texto."

16 "[...] quebra com a gramática e não força padrões de fala oral em prosa escrita. Mais importante ainda, não faz com que as palavras dos participantes da pesquisa pareçam 'inferiores', não programáticas e não pontuadas." 
com autores da literatura que discutem versos livres, entre eles Rosemary Block (1995) , ${ }^{17}$ Lorina construiu sua metodologia de trabalho. Segundo a autora, seu processo de construção se dá em três passos:

Firstly, I fully transcribe each recording into a verbatim transcript and at the same time, make separate transcription notes about the interview. Secondly, I copy the completed verbatim transcript into another document and begin conversion, by taking out all of my questions and responses. I then arrange the narrator's words on the page by using lines and space to convey the narrator's speech mannerisms: when they have paused, have gone silent or have changed topics. This step is what I call the unedited free verse. It is important to mention that while I do not edit the narrator's voice I do however, edit my voice so as not to interfere with the flow of the narrator's story. [...]. In the final step, the edited free verse, I make some minor editorial changes by omitting the narrator's false starts and repetition. (BARKER, 2010, p. 192-3). ${ }^{18}$

Todos esses passos, segundo ela, foram metodologicamente pensados, tendo em vista transpor para o papel a dinamicidade da oralidade. Para Lorina:

This style is used for the purpose of re-creating in written form the emotion and movement of words as they are spoken and received in conversation, as well as to re-capture the imagery of the interview, and what took place: the interaction between interviewer and participant. Free verse poetry is also used to preserve the traditional practice of oral history storytelling and to create a text version that conveys participant's lived experiences and history. (BARKER, 2010, p. 186). ${ }^{19}$

\footnotetext{
17 "Voiceprint: From Tape to Page: Keeping Faith with the Voice", Rosemary Block, 1995. Disponível em: <http://search.informit.org/documentSummary;dn=631820717818190; res=IELHSS; subject= Transportation>

18 "Em primeiro lugar, eu transcrevo totalmente cada gravação em uma transcrição literal e, ao mesmo tempo, faço anotações de transcrição separadas sobre a entrevista. Em segundo lugar, copio a transcrição completa para outro documento e começo a conversão, tirando todas as minhas perguntas e respostas. Em seguida, organizo as palavras do narrador na página, usando linhas e espaço para transmitir os maneirismos do discurso do narrador: quando eles pararam, ficaram em silêncio ou mudaram os tópicos. Este passo é o que eu chamo de verso livre não editado. É importante mencionar que, embora não editei a voz do narrador, contudo, editei minha voz para não interferir com o fluxo da história do narrador. [...]. No passo final, o verso livre editado, faço algumas pequenas mudanças editoriais ao omitir os falsos começos e repetições do narrador."

19 "Este estilo é usado com a finalidade de recriar de forma escrita a emoção e o movimento das palavras como são faladas e recebidas na conversa, bem como para recapturar as imagens da entrevista e o que aconteceu: a interação entre entrevistador e participante. A poesia do verso livre também é usada para preservar a prática tradicional da narrativa da história oral e para criar
} 
Essa discussão de Lorina é salutar para o argumento central deste artigo, tendo em vista que, se estamos escrevendo sobre as historicidades indígenas, precisamos também nos preocupar com a transposição dessas narrativas para os trabalhos acadêmicos. Dessa forma, trazê-las ao corpo do texto, buscando a fluidez, a emoção e a interculturalidade dessa escrita, somará aos esforços da superação das violências epistêmicas impostas às populações indígenas. A transcrição é o método mais usado e tem sido bem aceito nos meios acadêmicos - embora existam controvérsias. Entretanto, como quis destacar Lorina em seu texto, não é a única forma possível de fazer.

E como bem expressou Lorina no final de seu artigo, "[...] the written record as poetry, like art, music and dance, is yet another way of capturing and transmitting cultural knowledge and people's lived experiences. But before we can record myth, memories and Indigenous histories, as researchers it is crucial that we consider how this can be culturally, sensitively and ethically achieved" (BARKER, 2010, p. 200) ${ }^{20}$. A proposta de Lorina, além de propiciar o debate sobre as contribuições dos intelectuais indígenas para o campo de pesquisas sobre história indígena, também faz pensar aos pesquisadores não indígenas os "aprisionamentos do oral" quando do escrito. Dessa forma, a proposta da pesquisadora indígena - "re-creating in written form the emotion and movement of words" -, tem muita contribuição para a tarefa dos historiadores em tornar escrito o oral, na composição de seus textos, fruto de pesquisas construídas na relação com o Outro.

Ao resenhar a "autoridade etnográfica" na história da teoria antropológica, James Clifford sugere que a escrita etnográfica deve lutar conscientemente para não representar o "outro" abstrato e a-histórico. Segundo ele, imagens complexas e concretas da representação do outro são construídas "a partir das relações históricas específicas de dominação e diálogo". O autor aponta como, no desenvolvimento da disciplina, foi se conformando um mètier pautado na legitimidade do etnógrafo para acessar a alteridade cultural, do "uso" das línguas nativas, da

uma versão de texto que transmita as experiências vividas e a história do participante".

20 "O registro escrito como poesia, como arte, música e dança, é mais uma maneira de capturar e transmitir o conhecimento cultural e as experiências vivas das pessoas. Mas antes que possamos gravar mitos, memórias e histórias indígenas, como pesquisadores, é crucial considerarmos como isso pode ser alcançado cultural, sensivelmente e eticamente." 
ênfase dada a observação participante, ao recurso teórico da antropologia estrutural e que os representados tendiam a estar situados no "presente etnográfico".

Clifford explica que, no processo de "crescente prestígio do teórico-pesquisador de campo, colocou em segundo plano (sem eliminá-lo) uma série de processos e mediadores que haviam figurado de modo mais destacado nos métodos anteriores" (CLIFFORD, 2008, p. 32-3); segundo o autor, dessa empreitada "emergia, de modo não especificado, um texto representacional, escrito pelo observador participante" (CLIFFORD, 2008, p. 33). É nessa chave - a do "desaparecimento" dos informantes - que a discussão de Clifford é importante para este ensaio. Dessa forma, o autor advoga sobre as possibilidades para o discurso dialógico e polifônico, tema que também deve ser pensado pelos historiadores. Indaga o autor: "Como essas presenças autorais devem ser manifestas?" (CLIFFORD, 2008, p. 47). O caminho, segundo Clifford, é conceber a etnografia "[...] como uma negociação construtiva envolvendo pelo menos dois - e muitas vezes mais - sujeitos conscientes e politicamente significativos" (CLIFFORD, 2008, p. 41).

Assim, ao tornar o discurso etnográfico centrado na autoridade etnográfica do pesquisador participante, o que se construiu, segundo Clifford, foi um discurso etnográfico monofônico. "Na moderna e legítima monografia, não há, na verdade, quaisquer vozes fortes presentes, a não ser a do escritor" (CLIFFORD, 2008, p. 46). Em contrapartida ao que Clifford chamou de moderna e legítima monografia, em tom reflexivo, novos trabalhos têm trazido luz para "[...] novos meios de representar adequadamente a autoridade dos informantes" (CLIFFORD, 2008, p. 46). Nesse ponto, a história indígena, sob a perspectiva da história oral, pode ser muito propositiva, justamente, por ser a história oral fruto da necessidade de superar os silenciamentos a determinados grupos sociais e, dessa forma, tem se caracterizado por marcar os sujeitos da fala, trazendo-os para o corpo do texto enquanto sujeitos históricos, protagonistas das suas relações com o mundo.

As discussões de Clifford (2008) auxiliam nas inquietações que perpassam a escrita das histórias indígenas. Embora sua crítica esteja fundada no trabalho etnográfico, também sentimos, enquanto historiadores, que tal debate perpassa a nossa construção historiográfica. Assim, pesquisas realizadas com populações indígenas, a partir da história oral e da etnografia, não devem se esquivar dos debates sobre uma textualização dialógica e polifônica, permeando as complexidades de 
tornar o oral em escrito. Nessa questão, as reflexões de Lorina Becker conectam-se às propostas de Clifford (2008), e ajudam-nos a pensar sobre a utilização das oralidades na construção de trabalhos historiográficos sobre as histórias indígenas que estejam preocupados com os sujeitos da pesquisa na textualização desta.

Nesse saber-fazer historiográfico preocupado com os sujeitos históricos e protagonistas indígenas, ficam os desafios para os pesquisadores: quais mecanismos discursivos podem ser utilizados para transpor ao papel a dinâmica experiencial da pesquisa? Onde estão os sujeitos da pesquisa? Quais relações dialógicas são compostas na textualização do trabalho? Esses desafios, como tentamos evidenciar ao longo do texto, podem ser amadurecidos a partir das articulações metodológicas entre história oral e etnografia, como também quando tiramos a naturalização da transcrição e da transcriação e percebemos que outras possibilidades podem ser construídas.

Enquanto pesquisadores, precisamos ter clareza sobre a histórica violência epistêmica imputada aos povos indígenas, e a partir disso construir novos desafios metodológicos e teóricos para as nossas pesquisas, começando pelo diálogo interdisciplinar. Como bem colocou Oliveira:

[...] a interdisciplinaridade deve ser deliberadamente perseguida na prática e na teoria da pesquisa científica. No âmbito da academia brasileira, o sucesso de uma proposta assim depende menos de ações institucionais e mais da capacidade dos pesquisadores fazerem escola em seu sentido mais amplo, de estabelecerem uma relação de alteridade com disciplinas afins e de superarem as barreiras impostas pelos departamentos e campos do saber. Mais que um mero discurso acadêmico, para a história indígena, sobretudo se praticada nos centros tidos como "periféricos", a interdisciplinaridade se apresenta como condição sine qua non e como uma excelente oportunidade para a prática da pesquisa. (OLIVEIRA, 2012, p. 197-8).

E, dessa maneira, espera-se que a história esteja sempre aberta e disposta à interdisciplinaridade, evitando os riscos das caixas fechadas e aproximando-nos aos diálogos que só ampliam nossos horizontes de possibilidades para a escrita das histórias e a potencialidade que este ato proporciona. 


\section{CONSIDERAÇÕES FINAIS}

Assim como as "palavras dadas" de Kopenawa ganham novas dimensões quando desenhadas em peles de imagens, a apreensão das narrativas indígenas na construção das histórias indígenas pela historiografia precisa acessar as interdisciplinaridades. Dessa forma, as pesquisas realizadas com populações indígenas, que envolvem trabalhos de campo, precisam problematizar as metodologias pertinentes para compreender o universo de significados da alteridade indígena. Contudo, na disseminação dos estudos de história envolvendo as populações indígenas, podemos assentar algumas reflexões sobre as convergências e divergências entre as disciplinas histórica e antropológica. Assim, procuramos, ao longo do texto, marcar o engendramento da história oral com a etnografia enquanto frutífero diálogo interdisciplinar.

Trabalhar com os povos indígenas é, ou pelo menos deveria ser, substancialmente colocar-se em ambiente interdisciplinar. Tendo em vista que inúmeras variáveis compõem esse fazer, questões sobre linguística, antropologia, arqueologia, geografia, história emergem no decorrer da pesquisa, sobretudo a partir dos trabalhos de campo.

A história, como disciplina acadêmica, em diversos momentos incorporou as discussões antropológicas em sua reflexão teórica, o que provocou transformações significativas na historiografia. Na década de 1980, com a emergência da história cultural, as premissas da antropologia estruturalista passaram a influenciar uma guinada historiográfica mais sensível às categorias analíticas vinculadas à cultura. Entretanto a historiografia permaneceu, de modo geral, atrelada ao rigor metodológico de estatuto de veracidade das fontes documentais escritas. Dessa forma, a incorporação das fontes orais e das tradições orais ao escopo das fontes historiográficas ainda sofre certa crítica, entretanto, como vimos, está se constituindo e fortalecendo com as novas pesquisas apresentadas.

Os intelectuais indígenas, críticos de uma relação de assimetria epistêmica, têm tido papel significativo na proposição de outras formas de pesquisa. Lorina Barker desafia o status da transcrição na história indígena, propondo um diálogo com a literatura para trazer ao escrito mecanismos de torná-lo mais fluido e próximo do movimento da fala. Assim, a desnaturalização das formas de escrever o oral pode ser um caminho para novos desafios metodológicos e teóricos, frutíferos 
para a construção do protagonismo indígena nas páginas dos trabalhos acadêmicos. Sugerimos ainda, a partir das discussões de Clifford (2008), que a escrita posicionada na produção textual dialógica, entre sujeito pesquisador e sujeitos participantes da pesquisa, pode ainda ser um caminho ousado e amadurecido para a escrita das histórias indígenas, além de possibilitar contribuições epistêmicas ao saber-fazer da produção historiográfica. Entretanto cabe aos acadêmicos permitirem-se tais ousadias.

Em suma, a escrita das histórias indígenas tem muito a ganhar com o engendramento da história oral e da etnografia. Cada qual com seus desafios metodológicos podem auxiliar os pesquisadores no acesso as histórias indígenas. Essas histórias se compõem não apenas na oralidade, mas nas expressões corporais, nas pinturas que enfeitam os corpos, nas relações entre humanos e não humanos, no envolver-se com os territórios, elementos que não necessariamente são enunciados no ato de ouvir do pesquisador, mas também nos caminhos do olhar, e, nesse ponto, o encontro do historiador que trabalha com histórias indígenas com a etnografia torna-se uma aproximação necessária.

\section{REFERÊNCIAS}

ACEVES, Jorge E. Introducción: la historia oral contemporânea- una mirada plural. In: ACEVES, Jorge E. (Org.). Historia Oral: Ensayos y aportes de investigación. México: CIESAS, 1996.

ALBEERTI, Verena. Manual de História Oral. 3. ed. Rio de Janeiro: 2005.

ALMEIDA, Carina Santos de. Tempo, memória e narrativa Kaigang no oeste catarinense: a tradição Kaigang e proteção tutelar no contexto da transformação da paisagem na Terra Indígena Xapecó. 2015. 542 f. Tese (Doutorado em História) - Universidade Federal de Santa Catarina (UFSC), Florianópolis, 2015.

BARKER, Lorina. Using poetry to capture the Aboriginal voice in oral history transcripts. In: Passionate Histories: myth, memory and indigenous Australia. Australia: Ed. ANU; Press, 2010.

BRAND, Antonio Jacó. O impacto da perda da terra sobre a tradição Kaiowá/Guarani: os difíceis caminhos da palavra. 1997. Tese (Doutorado em História) - Pontifícia Universidade Católica do Rio Grande do Sul, Porto Alegre, 1997.

BLOCK, Rosemary. Voiceprint: from tape to page- keeping faith with the voice. Oral History Association of Australia Journal, Australia, v. 17, p. 65-73, 1995. 
BURGUIÈRE, André. A antropologia histórica. In: NOVAIS, Fernando A.; SILVA, Rogério Forastieri (Org.). Nova História em perspectiva. São Paulo: Cosac Naify, 2011. V. I.

CAVALCANTE, Thiago. Etno-história e história indígena: questões sobre conceitos, métodos e relevância da pesquisa. In: História, São Paulo, v. 30, n. 1, p. 349-71, jan./jun. 2011.

CLIFFORD, James. Sobre a autoridade etnográfica. In: A experiência etnográfica: antropologia e literatura no século XX. 3. ed. Rio de Janeiro: Editora UFRJ, 2008.

CRESPE, Aline Castilho. Mobilidade e temporalidade Kaiowá: do Tekoha à Reserva, do Tekoharã ao Tekoha. 2015. 427 f. Tese (Doutorado em História) - Universidade Federal da Grande Dourados (UFGD), Dourados, 2015.

CRUIKSHANK, Julie. Tradição oral e história oral: revendo algumas questões. In: FERREIRA, Marieta de Moraes; AMADO, Janaína (Org.). Usos e abusos da história oral. Rio de Janeiro: FGV Ed., 2006. p. 149-64.

CUNHA, Manuela Carneiro da (Org.). História dos índios no Brasil. São Paulo: Companhia das Letras, 1992.

FAUSTO, Carlos; HECKENBERGER, Michael (Org.). Time and memory in indigenous Amazonia: anthropological perspectives. Florida: University Press of Florida, 2007.

FREITAS, Edinaldo. Fala de índio, história do Brasil: o desafio da etno-história indígena. In: História Oral, São Paulo, n. 7, p. 181-97, jun. 2004.

HARTOG, François. Regimes de historicidade: presentismo e experiências do tempo. Tradução de Andréa S. de Menezes, Bruna Breffart, Camila R. Moraes, Maria Cristina de A. Silva e Maria Helena Martins. Belo Horizonte: Autêntica, 2014.

JOUTARD, Philippe. História oral: balanço da metodologia e da produção nos últimos 25 anos. In: FERREIRA, Marieta de Moraes; AMADO, Janaína (Org.). Usos e abusos da história oral. Rio de Janeiro: FGV Ed., 2006. p. 43-62.

KOPENAWA, Davi; ALBERT, Bruce. A queda do céu: palavras de uma xamã Yanomami. Tradução de Beatriz Perrone-Moisés. 1. ed. São Paulo: Companhia das Letras, 2015.

MACHADO, Ananda. Narrativas orais e línguas indígenas em Roraima: educação e preservação da memória e do patrimônio histórico. In: PORTUGAL, A. R.; HURTADO, L. R. (Org.). Representações culturais da América indígena. São Paulo: Editora UNESP; Cultura Acadêmica, 2015. (Desafios contemporâneos collection, p. 214-225).

A fala na língua wapichana como forma de protagonismo indígena na história. In: SIMPÓSIO NACIONAL DE HISTÓRIA-Contra os preconceitos: história e democracia, 29., 24-28 jul. 2017, Brasília, DF. Anais... Brasília: UNB, 2017. Disponível em: <http://www. snh2017.anpuh.org/site/anais>. Acesso em: jun. 2018. 
MAURO, Victor Ferri. História, território e identidade Krahô-Kanela. 434 f. Tese (Doutorado em História) - Universidade Federal da Grande Dourados, Dourados, 2016.

MCGRATH, Ana. Deep Histories in Time, or Crossing the Great Divide? In: MCGRATH, Ana; JEBB, Mary Anne. Long history, deep time: deepening histories of place. Austrália: Ed. ANU; Press, 2015.

MEIHY, José Carlos Sebe Bom. Manual de História oral. 4. ed. rev. e ampl. São Paulo: Loyola, 2004.

. Canto de morte Kaiowá: história oral de vida. São Paulo: Loyola, 1991.

MILLER, Bruce Granville. Oral history on trial: recognizing Aboriginal Narratives in the Courts. Toronto: Ed. UBC, 2011.

MONTEIRO, John Manuel. O desafio da História Indígena no Brasil. In: SILVA, Aracy Lopes da; GRUPIONI, Luís Donisete Benze (Org.). A temática indígena na escola: novos subsídios para professores de 1ำ e 2o graus. Brasília: MEC; MARI; UNESCO, 1995.

OLIVEIRA, Jorge Eremites de. A História Indígena no Brasil e em Mato Grosso do Sul. In: Espaço Ameríndio, Porto Alegre, v. 6, n. 2, p. 178-218, jul./dez. 2012.

OLIVEIRA, Roberto Cardoso de. O trabalho do antropólogo. 2. ed. São Paulo: Ed. UNESP, 2000.

PORTELLI, Alessandro. Tentando aprender um pouquinho: algumas reflexões sobre a ética na história oral. Projeto História - Revista do Programa de Estudos Pós-Graduados em História, São Paulo, v. 15, p. 13-49, jul./dez. 1997.

SILVA, Joana Aparecida Fernandes; SILVA, Giovani José da. História indígena, antropologia e fontes orais: questões teóricas e metodológicas no diálogo com o tempo presente. História Oral, v. 13, n. 1, 2010.

TEAO, Kalna Mareto. Território e Identidade dos Guarani Mbya do Espírito Santo (19672006). 234 f. Tese (Doutorado em História) - Universidade Federal Fluminense, Rio de Janeiro, 2015.

. Juntos na terra, juntos na luta e juntos na História: relações interétnicas entre Tupinikim e Guarani mbya no Espírito Santo. In: SIMPÓSIO NACIONAL DE HISTÓRIA contra os preconceitos: história e democracia, 29., 24-28 jul. 2017, Brasília, DF. Anais... Brasília: UNB, 2017. Disponível em: <http://www.snh2017.anpuh.org/site/anais>. Acesso em: jun. 2018.

TRIMBLE, Charles; SOMMER, Barbara; QUINLAN, Mary Kay. The American Indian oral history manual: making many voices heard. New York: Routledge, 2008. 
VANSINA, Jan. Oral tradition as History. Wisconsin: University of Wisconsin Press, 1985.

YOW, Valerie Raleigh. Recording oral History: a guide for the Humanities and Social Sciences. Estados Unidos: Ed. Altamira, 2005.

\section{Sobre os autores:}

João Mitia Antunha Barbosa: Doutor em Direito pela Université d’Angers e pela Faculdade de Direito da Universidade de São Paulo. Atualmente é indigenista especializado da Fundação Nacional do Índio (FUNAI). E-mail: mitiaantunha@gmail.com

Roseline Mezacasa: Doutoranda do Programa de Pós-Graduação em História, linha de pesquisa História indígena, etnohistória e arqueologia. Docente do curso de História da Universidade Federal de Rondônia (UNIR), campus de Rolim de Moura. E-mail: roselinemezacasa@hotmail.com

Marcelo Gonzalez Brasil Fagundes: Doutorando do Programa de Pós-Graduação em História, linha de pesquisa História indígena, etnohistória e arqueologia. Docente do curso de História da Universidade Federal do Tocantins (UFT), campus de Porto Nacional. E-mail: marcelogbrasil@gmail.com 
